\title{
Growth of Atlantic salmon Salmo salar after intraperitoneal administration of vaccines containing adjuvants
}

\author{
P. J. Midtlyng *, A. Lillehaug \\ National Veterinary Institute, PO Box 8146 Dep., N-0033 Oslo, Norway
}

\begin{abstract}
Growth of Atlantic salmon after intraperitoneal (i.p.) administration of adjuvanted vaccines was studied using groups of individually tagged fish held together in one tank or pen under commercial farming conditions. Parallel experiments were initiated at 2 freshwater sites and 1 marine site. Trivalent (vibriosis, cold water vibriosis and furunculosis) vaccines containing oil or $\beta-1,3$ glucan as adjuvants were used for immunisation of pre-smolts, whereas identical formulations containing furunculosis antigens only were used in growers. Control fish remained unvaccinated. No outbreak of bacterial or viral disease was experienced at any of the sites. At all sites, the highest daily growth rate was recorded in unvaccinated fish. At one site, the average weight of post-smolts that had received oiladjuvant vaccine was significantly reduced by $345 \mathrm{~g}(23 \%)$ after $15 \mathrm{mo}$. Impaired growth rate was associated with increasing severity of intra-abdominal lesions as determined during necropsy. At the second post-smolt site and in growers, weight development and growth rates were non-significant between groups throughout the study. The results indicate that intraperitoneal administration of oiladjuvanted vaccines may retard growth of farmed Atlantic salmon, although the extent of this effect may vary between sites. Unidentified factors coinciding with vaccination are thought to have caused the highly variable results seen between parallel sites in this study.
\end{abstract}

KEY WORDS: Aquaculture $\cdot$ Salmo salar Vaccination · Side-effects · Growth · Intra-abdominal lesions

\section{INTRODUCTION}

In commercial farming of Atlantic salmon Salmo salar L., vaccination against bacterial diseases is required to avoid major disease epizootics and economic losses (Press \& Lillehaug 1995). After the introduction of adjuvanted, injectable bacterins to protect effectively against furunculosis (Midtlyng et al. 1996), polyvalent vaccine formulations prepared with oiladjuvant systems have been widely adopted in salmon aquaculture (Lillehaug 1997). Intra-abdominal adhesions have, however, been recognised as a side-effect of this treatment (Midtlyng 1996). The character of these lesions raises questions as to possible long-term effects on fish growth. Experimental studies of this subject using alum-adjuvanted bacterins have yielded

- Present address: VESO, PO Box 8109 Dep., N-0032 Oslo, Norway. E-mail: paul.midtlyng@veso.no contradictory results (Horne et al. 1984, Lillehaug et al. 1992, Mulvey et al. 1995). The present study was initiated to evaluate possible growth effects of injectable vaccines; in particular those containing oil adjuvants, in Atlantic salmon reared under semi-commercial conditions.

\section{MATERIALS AND METHODS}

Atlantic salmon of the Norwegian Salmon Breeders' (NLA) strain were obtained from 1 breeding centre and 2 commercial fish farms. At 2 sites (I and II), the fish were vaccinated as pre-smolts, whereas the third study population (site III) was vaccinated as growers, after being reared in seawater for approximately 1 yr. The study populations consisted of individually tagged fish belonging to different vaccination groups, which were kept together in one tank or net pen population 
throughout the experiment. Commercially available vaccines prepared with oil or glucan as adjuvants were used for immunising the fish (Table 1). A summary of the experimental conditions and husbandry treatment of each site is given in Table 2 .

At all sites, the fish were anaesthetised, individually marked by intraperitoneal (i.p.) implantation of passive integrated transponder (PIT) tags, weighed, and vaccinated in one sequence, on the first day of the trial. Vaccine was injected intraperitoneally through the midline, 1 to 2 fin lengths anterior to the pelvic fin base. At sites I and II, the fish were kept in fresh water at ambient temperature until sea transfer, which took place 8 to 9 wk after vaccination. Weight measurements involving anaesthesia and PIT tag readings were performed several times during the observation period (see Table 2). At sites I and II, the severity of intra-abdominal adhesions was determined visually according to Midtlyng et al. (1996) when the fish were harvested, 9 mo after the final weight measurement. Individual fish were thereby given a score from 0 (no adhesions) to 6 (most severe adhesions) during evisceration. At all sites, the fish received commercial dry pelleted feed (Skretting) of appropriate size at an average daily amount of $1 \%$ of the estimated biomass, which was adjusted according to appetite by manual feeding.
Site I. In this experimental research facility, 500 previously unvaccinated fish were anaesthetised in a metacaine solution and allocated to 4 vaccination groups before vaccination and implantation of PIT tags (block randomisation; block size $=5$ ). Every fifth fish was marked by clipping the adipose fin and vaccinated with the same vaccine as group 63 (Apoject 3-Fural) without being PIT-tagged. These fish, which were designated cohabitants, were included to serve as controls with respect to the tagging method. Fish identity was read and weight was measured to the nearest gram using an electronic scale before the fish was placed in a $1.5 \times 1.5 \mathrm{~m}$ tank supplied with running fresh water for recovery and on-rearing. After transfer to the sea, the population was kept separate in a small experimental pen for approximateiy 1 yr, whereafter ii was transferred to a medium-size experimental unit. During the seawater period, individual fish weights were determined to the nearest gram on 3 occasions. Infestations with sea lice were controlled by Nuvan bath treatment, and an in-feed treatment against tapeworm infestation was administered following the second intermediate weighing.

Site II. In this commercial facility, approximately 1000 fish were pre-selected by size grading prior to commencement of the trial. Approximately 6 mo ear-

Table 1. Commercially available vaccines selected for the study of post-vaccination growth in farmed Atlantic salmon

\begin{tabular}{|c|c|c|c|c|}
\hline $\begin{array}{l}\text { Vacc. } \\
\text { group }\end{array}$ & $\begin{array}{l}\text { Vaccine } \\
\text { used }\end{array}$ & Antigen(s) & Adjuvant & $\begin{array}{l}\text { Injected } \\
\text { volume }\end{array}$ \\
\hline $\begin{array}{l}61 \\
63\end{array}$ & $\begin{array}{l}\text { Apoject } 1 \text {-Fural } \\
\text { Apoject } 3 \text {-Fural }\end{array}$ & $\begin{array}{l}\text { Aeromonas salmonicida } \\
\text { A. salmonicida, Vibrio anguillarum } \mathrm{O} 1+\mathrm{O} 2, \text { V. salmonicida }\end{array}$ & $\begin{array}{l}\text { Squalene oil system } \\
\text { Squalene oil system }\end{array}$ & $0.2 \mathrm{ml}$ \\
\hline $\begin{array}{l}21 \\
23\end{array}$ & $\begin{array}{l}\text { Biojec } 1500 \\
\text { Biojec } 1900\end{array}$ & $\begin{array}{l}\text { A. salmonicida } \\
\text { A. salmonicida, } V \text { anguillarum } \mathrm{O} 1+\mathrm{O} 2, V \text {. salmonicida }\end{array}$ & $\begin{array}{l}\text { Mineral oil system } \\
\text { Mineral oil system }\end{array}$ & $0.2 \mathrm{ml}$ \\
\hline $\begin{array}{l}11 \\
13\end{array}$ & $\begin{array}{l}\text { Norvax fur } \\
\text { Norvax triple }\end{array}$ & $\begin{array}{l}\text { A. salmonicida } \\
\text { A. salmonicida, } V \text {. anguillarum } \mathrm{O} 1+\mathrm{O} 2, V \text {. salmonicida }\end{array}$ & $\begin{array}{l}\beta-1,3 \text { glucan }^{b} \\
\beta-1,3 \text { glucan }^{b}\end{array}$ & $0.2 \mathrm{ml}$ \\
\hline 99 & Unvaccinated & None & na & na \\
\hline
\end{tabular}

Table 2. Site and experimental setup of 3 parallel sites for study of post-vaccination growth in farmed Atlantic salmon

\begin{tabular}{|llll|}
\hline & Site I & Site II & Site III \\
\hline Vaccination date & 24 March & 19 March & 6 May \\
Water temp. at vaccination $\left({ }^{\circ} \mathrm{C}\right)$ & 6.3 & 4.9 & 7.2 \\
Average weight $(\mathrm{g}) \pm \mathrm{SD}$ & $47.3 \pm 10.4$ & $41.6 \pm 3.9$ & $2335 \pm 537$ \\
Groups included & $63,23,13,99$, Cohabitants & $63,13,99$, Cohabitants & $61,21,11,99$, Cohabitants \\
Time from vaccination to sea transfer $(\mathrm{d})$ & 55 & 60 & 500 \\
Size of net pens $\left(\mathrm{m}^{3}\right)$ : initially & 27 & 144 & First: 88 \\
after ongrowth & 125 & First: 227 & 3 \\
Time to weight measurements (d) & First: 196 & Second: 446 & 3 \\
Second: 293 & 15 & \\
Observation period in total (mo) & Third: 456 & 24 & \\
Time from vaccination to harvest $(\mathrm{mo})$ & 15 & & \\
na: not applicable & 24 & & \\
\hline
\end{tabular}


lier, these fish had been vaccinated against vibriosis and cold water vibriosis by immersion using a commercial bacterin (Apovax Duo). Anaesthesia, tagging, weighing, and vaccination procedures were as at site I, except that for commercial reasons only one oil-adjuvant vaccine group was included. For each 3 individually PIT-tagged fish, which were marked by adipose fin clip before they were allocated to one of the vaccination groups, another 5 cohabitant fish were vaccinated with Apoject 3-Fural without being PIT-tagged or marked. After sea transfer, this population was initially held in a net pen of approximately $125 \mathrm{~m}^{3}$ before being transferred to a commercial size pen after 12 mo. Individual fish weights to the nearest $10 \mathrm{~g}$ were read on 2 occasions during the observation period. Infestations with sea lice were controlled by cohabiting wrasse.

Site III. In this commercial marine facility, the recruitment population had been immunised against vibriosis and cold water vibriosis by immersion during fresh water rearing more than 12 mo earlier. The fish were unvaccinated against furunculosis, and recurrent outbreaks of this disease 4 to 7 mo earlier had been controlled by medicated feed. Four weeks prior to commencement of the study, approximately 500 study fish of approximately uniform size were pre-selected and isolated in a separate pen, whereas the remaining fish, designated cohabitants, were immunised with the same vaccine as group 21, Biojec 1500 . After anaesthesia using a benzocaine solution, the study fish were randomly allocated to groups as earlier described, vaccinated, PIT-tagged, weighed to the nearest $10 \mathrm{~g}$, and marked by clipping the adipose fin before being released to recover in a separate pen. Approximately $10 \mathrm{~d}$ post vaccination, the study population was combined with the cohabitants and subsequently maintained in a commercial size pen. Due to market considerations, the population was harvested 3 mo later, and individually weighed after bleeding, but before evisceration. Feeding was initiated 1 wk after vaccination, reaching normal intensity of approximately $1 \%$ of the estimated biomass per day after $3 \mathrm{wk}$. Two weeks before harvest, feeding was discontinued.

Statistical analysis of data. Processing and statistical analysis of data were done on a site-by-site basis. The daily growth rate (dgr) was expressed for each fish as a percentage of its initial weight according to the following formula:

$$
d g r=100(\ln W 2-\ln W 1) / n
$$

where $W 1$ and $W 2$ are the weights of a fish at 2 subsequent measurements, and $n$ is the number of days between the 2 measurements. Weight development of groups over time was further analysed by repeated measurement analysis of variance using Wilk's lambda test for significance.
Comparison of weights and average daily growth rates was done across all groups, using 1-way analysis of variance (ANOVA) with non-parametric (KruskalWallis) $p$-values if variances were found to differ or if data were not normally distributed. Chi-square analysis or Fisher's exact tests performed across all groups were employed for comparison of mortality and other discontinuous data. The p-value thus represents the probability that the observed distribution of data points between groups is due to random variation alone, whereas information on which groups are significantly different from others is indicated through confidence limits. P-values of 0.05 or less were considered significant. Calculations of statistical power were done according to Frankena et al. (1990).

\section{RESULTS}

\section{Disease record and survival}

No mortalities of individually tagged fish occurred during the first $24 \mathrm{~h}$ after vaccination at any site. None of the populations experienced any outbreak of bacterial or viral disease during the observation period, and kidney samples drawn from fish that occasionally died yielded no growth of common salmon bacterial pathogens. A summary of the mortality data (Table 3) shows that losses were generally low except at site II, where a significant number of vaccinates died during the first observation period. The majority of these fish died with non-specific signs before sea transfer. Apart from this, no significant mortality differences were found between groups.

During the first months in the sea, a number of nonor poor-feeding fish (designated pinheads) were observed in site II, some of which eventually succumbed before the first weight measurement. At site I, a few such fish died after treatment against sea lice. After intermediate weighings, these fish were deemed to be unfit for further rearing, and were killed and necropsied. The distribution of pinheads was significant at site II, being highest among the oil-adjuvant group and the cohabitants, which had received the same oiladjuvanted vaccine. The majority of pinheads carried moderate to severe intra-abdominal adhesions similar in appearance to those recently described by Poppe \& Breck (1997).

\section{Analysis of weight development}

At all sites, weight differences recorded between groups at the time of vaccination were minor and nonsignificant. 
Table 3. Salmo salar. Number of fish at vaccination, cumulative mortality, number of pinheads removed after weight measurements, and intraabdominal lesion scores determined at harvest in groups of Atlantic salmon being held in parallel study sites. Group identity is according to Table 1 $P$-values of 0.05 or less were considered significant, and refer to statistical lesting across all groups

\begin{tabular}{|c|c|c|c|c|c|c|}
\hline \multirow[t]{2}{*}{ Site } & \multirow[t]{2}{*}{ Group } & \multirow{2}{*}{$\begin{array}{c}\text { Vaccination } \\
n\end{array}$} & \multirow{2}{*}{$\begin{array}{c}\text { Cumulative } \\
\text { mortality }\end{array}$} & \multirow{2}{*}{$\begin{array}{l}\text { No. of } \\
\text { pinheads }\end{array}$} & \multicolumn{2}{|c|}{ Lesion score } \\
\hline & & & & & Average & $\mathrm{n}$ \\
\hline \multirow[t]{6}{*}{ I } & 63 & 100 & 12 & 1 & 2.1 & 32 \\
\hline & 23 & 100 & 13 & 1 & 2.1 & 34 \\
\hline & 13 & 100 & 16 & 4 & 1.1 & 29 \\
\hline & 99 & 100 & 15 & 1 & 0.2 & 35 \\
\hline & Cohabitants & 101 & 17 & 3 & nd & \\
\hline & p-value & & 0.86 & 0.40 & $<0.001$ & \\
\hline \multirow[t]{5}{*}{ II } & 63 & 100 & 20 & 12 & 1.4 & 35 \\
\hline & 13 & 98 & 18 & 4 & 2.8 & 41 \\
\hline & 99 & 99 & 4 & 0 & 0.4 & 50 \\
\hline & Cohabitants & 500 & 57 & 29 & nd & \\
\hline & p-value & & $<0.01$ & $<0.01$ & $<0.001$ & \\
\hline \multirow[t]{6}{*}{ III } & 61 & 127 & 1. & nd & nd & \\
\hline & 21 & 128 & 1 & nd & nd & \\
\hline & 11 & 126 & 2 & nd & nd & \\
\hline & 99 & 127 & 1 & nd & nd & \\
\hline & Cohabitants & -10000 & nd & nd & nd & \\
\hline & p-value & & 1.0 & & & \\
\hline \multicolumn{7}{|c|}{ nd: not determined } \\
\hline
\end{tabular}

site I. At site II, fish that had received oiladjuvant vaccine grew significantly poorer $(p<0.001)$ than the control group. When tested by Wilk's lambda, the poorer weight development of the glucan vaccine group was borderline non-significant ( $p=0.06$ ) when compared to the unvaccinated controls. At site III, the test confirmed that differences were nonsignificant.

At sites I and II, the statistical tests further confirmed that weight differences between groups that had received vaccine with or without PIT tags (group 63 vs cohabitants) were non-significant throughout the trial.

\section{Analysis of daily growth rates of individual fish}

The average daily growth rate $(d g r)$ of the various groups of post-smolts from site I during the first observation period was between 0.997 and 1.013 , with a non-significant distribution among groups

At site I, all groups displayed a uniform growth pattern, as seen in Fig. 1. The average weight of the unvaccinated group remained highest throughout the trial, with non-significant differences reaching a maximum of $84 \mathrm{~g}$ (1435 vs $1351 \mathrm{~g} ; p=0.63)$ at the third weight measurement.

At site II, the average weight of the oil-adjuvant vaccine group was $120 \mathrm{~g}$ lower than that of the unvaccinated controls (491 vs $371 \mathrm{~g}$ : $\mathrm{p}<0.001$ ) at the first intermediate weighing. Differences between control fish and the glucan-adjuvant vaccine group (491 vs $430 \mathrm{~g} ; \mathrm{p}=0.002$ ), and between the glucan and the oil-adjuvant vaccine group (430 vs $371 g_{i} p=0.004$ ) were both significant. At the second weighing, the difference between the oiladjuvant vaccine group and the controls was $345 \mathrm{~g}$ ( 1505 vs $1159 \mathrm{~g}$; $\mathrm{p}<0.001$ ), representing a $23 \%$ lower average weight than the unvaccinated fish.

At site III, the average weight of the control group was higher than, but not significantly different from either of the 2 vaccinated groups at termination of the trial (3576 vs 3414 or $3401 \mathrm{~g}$, respectively).

Statistical analysis using a repeated measurement technique confirmed that there were no significant differences in weight development of the groups at
Table 4. Salmo salar. Average daily growth rate over 7 mo in Atlantic salmon belonging to various vaccination groups held at 3 parallel study sites. Group identity is according to Table 1. P-values of 0.05 or less were considered significant, and refer to statistical testing across all groups

\begin{tabular}{|ccccccc|}
\hline Site & Group & $\mathrm{n}$ & Mean & $\mathrm{Cl}$ & Min & Max \\
\hline I & 63 & 86 & 0.998 & $0.969-1.027$ & 0.451 & 1.315 \\
& 23 & 90 & 0.997 & $0.967-1.216$ & 0.097 & 1.216 \\
& 13 & 93 & 0.999 & $0.970-1.028$ & 0.369 & 1.230 \\
& 99 & 87 & 1.013 & $0.981-1.045$ & 0.500 & 1.316 \\
& p-value & & 0.86 & & & \\
II & 63 & 79 & 0.930 & $0.890-0.970$ & 0.336 & 1.185 \\
& 13 & 67 & 1.003 & $0.962-1.044$ & 0.066 & 1.298 \\
& 99 & 83 & 1.071 & $1.047-1.095$ & 0.611 & 1.270 \\
& p-value & & $<0.001$ & & & \\
III & 61 & 67 & 0.418 & $0.385-0.451$ & 0.124 & 0.824 \\
& 21 & 63 & 0.441 & $0.411-0.471$ & 0.149 & 0.680 \\
& 11 & 66 & 0.415 & $0.382-0.448$ & 0.051 & 0.805 \\
& 99 & 69 & 0.451 & $0.421-0.481$ & 0.373 & 0.710 \\
& p-value & & 0.19 & & & \\
& & & & & &
\end{tabular}



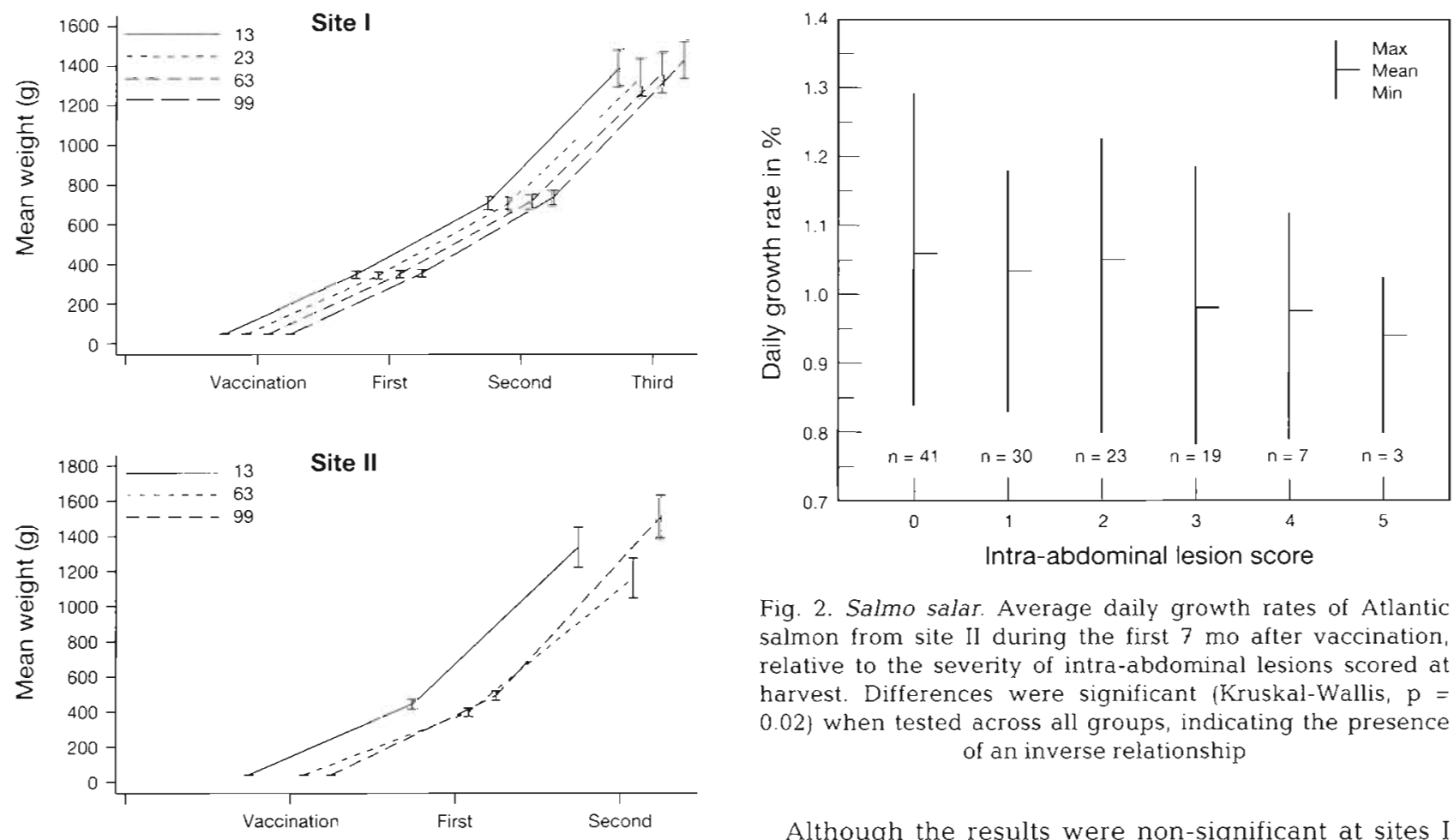

Fig. 2. Salmo salar. Average daily growth rates of Atlantic salmon from site II during the first 7 mo after vaccination, relative to the severity of intra-abdominal lesions scored at harvest. Differences were significant (Kruskal-Wallis, $\mathrm{p}=$ 0.02) when tested across all groups, indicating the presence of an inverse relationship

Although the results were non-significant at sites I and III, the unvaccinated group displayed the highest average daily growth rate at all sites of the study. The

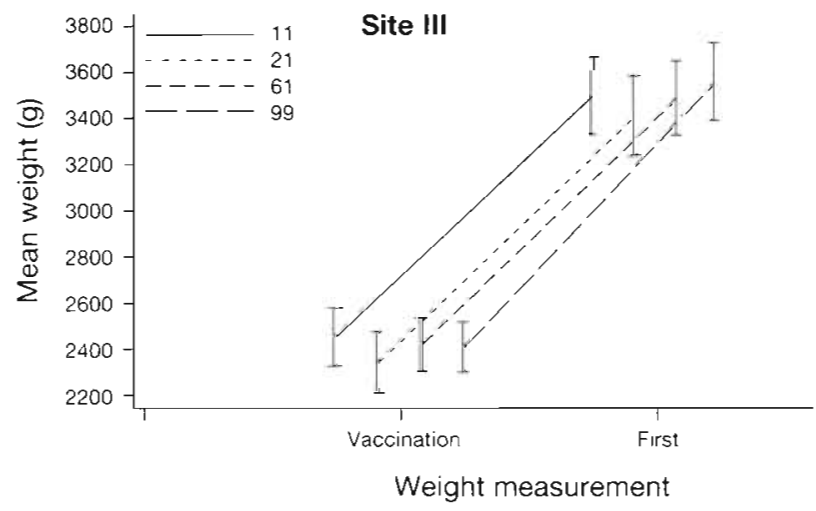
probability of this ranking being a purely random effect proved low $(p=0.02)$.

\section{Intra-abdominal lesions}

Following the occurrence of early sexual maturation of fish after termination of the weight measurements at sites I and II, the populations were graded and only non-maturing individuals were kept for ongrowth to commercial harvest size. Thus, only half of the remaining fish from the growth trial were available for evaluation of intra-abdominal lesions at slaughter. None or only minor adhesions were observed in unvaccinated fish, confirming that the PIT tags used for identification of individual fish were inert. The most severe lesions were observed in fish of vaccination group 63 (Table 3).

In fish from site II, a significant ( $p=0.02$ ) inverse association between intra-abdominal lesion score and average daily growth rate was established (Fig. 2).

\section{DISCUSSION} harvest since they were unidentifiable by electronic means.

Analyses to test if the occurrence of dropouts would confound the results and if interaction existed between initial weight and daily growth rate were negative.

The results obtained here demonstrate that impaired growth may occur after intraperitoneal vaccination of Atlantic salmon with adjuvanted bacterins. Being specifically designed to analyse the growth perfor- 
mance of individual fish, the present results therefore confirm earlier reports of adverse growth effects after i.p. vaccination of salmonids (Horne et al. 1984, Lillehaug et al. 1992). Whereas most previous studies were performed with alum-adjuvanted bacterins, the present data show that even more severe growth effects may occur with oil-adjuvanted vaccine formulations. We believe that the lack of previous reports on the effect of such vaccines on growth (see Midtlyng 1997) is due to the fact that such vaccines were previously confined to experimental work, without being used to a significant extent in commercial aquaculture. Despite the results being borderline non-significant when using the repeated measurement test over the entire observation period, the statistical analysis of daily growth rates showed that significant growth impairment also occurred in the glucan-adjuvanted vaccine group during the first period following vaccination. Retarded growth due to glucan-adjuvanted fish vaccines has to our knowledge not been reported earlier.

As both vaccinates and unvaccinated controls were individually anaesthetised and PIT-tagged at the same time, growth effects are thought to be specifically associated with the administration of vaccine, and not due to the anaesthesia and tagging procedures. In contrast to methods employed in earlier studies, the statistical analysis of growth effects on individual fish basis allowed for adjustment of individual fish mortalities. Our practice of keeping all groups in one pen ensured that all fish were offered the same opportunity to feed. However, the method cannot clarify if differences in feed intake or differences in feed conversion caused the observed effects.

The magnitude of the effects observed in fish having received oil-adjuvanted vaccine at site II, namely a more than $20 \%$ weight reduction compared to controls after 1 yr of seawater rearing, is a highly relevant observation for commercial salmon aquaculture. The number of pinheads that succumbed before the first weight measurement and consequently dropped out of the study adds to concerns about side-effects of vaccination. At this site, impaired growth and occurrence of pinheads together produced a reduced biomass compared to the control group of $45.7 \mathrm{~kg}$ in group 63 , and $38.3 \mathrm{~kg}$ in group 13. In comparison to the output of $123.4 \mathrm{~kg}$ from the control group, these figures represent a $37 \%$ and a $31 \%$ reduction in biological production, respectively.

It is important to realise, however, that the present findings were obtained in a farming environment without significant infection pressure on the unvaccinated fish, as the experimental pens were situated within thoroughly vaccinated populations offering strong population immunity. Most likely, a challenge by any of the diseases being immunised against would have affected the groups very differently, causing loss of appetite, clinical signs and losses predominantly in unprotected fish. Unlike the situation experienced in the present study, a challenge environment is thought to give a growth advantage to vaccinated fish, and a relative disadvantage to unvaccinated fish.

The divergent results between sites I and II indicate that the negative impact on growth from vaccine side effects may be highly variable. Given the variation within groups, the number of observations obtained from site I possess $80 \%$ power to reveal weight differences of approximately $120 \mathrm{~g}(12.5 \%)$ at the third weighing. For site III, the limit of detection at $80 \%$ power would be approximately $200 \mathrm{~g}$, corresponding to $13.9 \%$ weight reduction. The non-significant outcomes from these sites are therefore no evidence of the absence of growth effects, but do suggest that negative growth effects exceeding 12 to $14 \%$ are inconsistent with intraperitoneal vaccination in general, or with the general performance of the vaccine used for group 63. Caution should therefore be taken in blaming the vaccine alone for the outcome in site II. Some biological factor coinciding with the immunisation appears to be present in this site. The size of the fish, water temperature, or technique of vaccination does not seem to be of major relevance, as these factors were largely standardised between sites I and II. Although the present study failed to point out specific factors or to detect any fish pathogens, we suggest that the effects of subclinical or latent infections should be further investigated.

As seen from Fig. 2, negative growth effects seem to be associated with severe injection-site lesions of score 4 and higher. From the character and location of lesions within the abdominal cavity, inflammation, adhesions and granulomata are thought to impair the functions of the digestive tract, to cause loss of appetite, and prolonged or in some cases even permanent non-feeding of individual fish. Although the association between impaired growth and intra-abdominal adhesion score is evident from the present data, the number of fish with scores higher than 3 is low and thus suboptimal for evaluating the scoring system as such. Most likely, this is because high-score pinheads dropped out earlier in the study or were removed during initial samplings. Thus, the suitability of the scoring method to predict negative growth effects should be further evaluated using an experimental setup avoiding such bias.

The minor pathological findings in unvaccinated, PIT-tagged fish confirm that the tagging procedure itself was unlikely to give bias to the results. The high number of dropouts at site III is thought to be caused 
by improper application of tags rather than tag failure, as only a few tags were recovered from unidentified but adipose fin-clipped fish at harvest. The poor recovery did not, however, affect the distribution of initial weights between vaccination groups and was therefore deemed not to confound the analysis of daily growth rates.

In conclusion, the results from the present study confirm that i.p. vaccination of Atlantic salmon with adjuvanted vaccines involves a risk of impaired growth. Growth effects were shown to vary depending on vaccine formulation and site, occasionally representing more than $20 \%$ average weight reduction 15 mo after vaccination with a multivalent oil adjuvant vaccine. For individual fish, reduced weight was associated with severe intra-abdominal lesions as determined visually during evisceration.

Acknowledgements. The authors thank VESO AS (the Norwegian veterinary vaccine distributor), Alpharma Aquatic Animal Health, Ltd and Biomed, lnc. (now part of Alpharma Aquatic Animal Health) for providing financial support for the study. Owners and staff of Akvaforsk AS, Svanoy Stiftelse and AS Fiskekultur are also thanked for their skilful maintenance of the fish and their helpful technical assistance. Thanks are also due to Dr Stig Larsen for guidance regarding repeated measurement statistics, and to Prof. Ashild Krogdahl and Prof. Adrian Smith from the Norwegian College of Veterinary Medicine for providing helpful suggestions with the manuscript.

Editorial responsibility: David Bruno, Aberdeen, Scotland, UK

\section{LITERATURE CITED}

Frankena K, Noordhuizen JP, Willeberg P, van Voorthuysen PF, Goolema JO (1990) EPISCOPE; computer programs in veterinary epidemiology. Vet Rec 126:573-576

Horne MT, Roberts RJ, Tatner M, Ward P (1984) The effects of the use of potassium alum adjuvant in vaccines against vibriosis in rainbow trout, Salmo gairdneri Richardson J Fish Dis 7:91-99

Lillehaug A (1997) Vaccination strategies in seawater cage culture of salmonids. In: Gudding R, Lillehaug A, Midtlyng PJ, Brown $F$ (eds) Fish vaccinology. Dev Biol Stand 90:401-408

Lillehaug A, Lunder T, Poppe TT (1992) Field testing of adjuvanted furunculosis vaccines in Atlantic salmon, Salmo salar L. J Fish Dis 15:485-496

Midtlyng PJ (1996) A field study on intraperitoneal vaccination of Atlantic salmon (Salmo salar L.) against furunculosis. Fish Shellfish Immunol 6:553-565

Midtlyng PJ (1997) Vaccinated fish welfare: protection versus side-effects. In: Gudding $R$, Lillehaug A, Midtlyng PJ, Brown $F$ (eds) Fish vaccinology. Dev Biol Stand 90:371-379

Midtlyng PJ, Reitan LJ, Speilberg L (1996) Efficacy and sideeffects of injectable furunculosis vaccines in Atlantic salmon (Salmo salar L.). Fish Shellfish Immunol 6:335-350

Mulvey B, Landolt ML, Busch RA (1995) Effects of potassium sulphate (alum) used in an Aeromonas salmonicida bacterin on Atlantic salmon, Salmo salar L. J Fish Dis 18: 495-506

Poppe TT, Breck O (1997) Pathology of Atlantic salmon Salmo salar intraperitoneally immunized with oil-adjuvanted vaccine. A case report. Dis Aquat Org 29:219-226

Press CM, Lillehaug A (1995) Vaccination in European salmonid aquaculture: a review of practices and prospects. Brit Vet J 151:45-69

Submitted: August 4, 1997; Accepted: December 15, 1997 Proots received from author(s): February 19, 1998 